\title{
Primeras notas sobre «Notes de viatges». Relatos viajeros de Ramon Vilaró i Guillem
}

\author{
ÓSCAR FERNÁNDEZ POZA
}

(UCM)

\section{PREÁMBULO}

En el presente artículo pretendemos recuperar los catorce relatos viajeros del empresario barcelonés Ramon Vilaró i Guillemí por tierras italianas, publicados en la revista barcelonesa El Teatre Català (1912-1917), durante un espacio de tiempo de dos años. Durante este periodo, nuestro autor realiza varios viajes a Italia enmarcados dentro de su labor profesional.

Antes de entrar en el estudio de esas crónicas viajeras, acojámonos a las palabras de Idoia Arbillaga, sobre el género literario que nos ocupa:

El libro de viajes es un género ensayístico que presenta una predeterminación temática la cual requiere eminentemente la descripción de un viaje real que es representado mediante el desarrollo de un itinerario topográfico pleno, parcial o implícito. Su dispositio se constituye cardinalmente por razón del discurso descriptivo, seguido del narrativo, y su elocutio se manifiesta mediante la preferencia por la primera persona, por la virtud de la perspicuitas, por el estilo medio o bien epistolar, y por el uso característico, si no privativo, de ciertas figuras retóricas como el recurso a otras obras y otros procedimientos formales $^{1}$

Como iremos comprobando a lo largo de este artículo, muchas de las características del género aquí marcadas, están presentes en los textos de Vilaró. Estas crónicas se acercarían más, si en un futuro fueran de nuevo publicadas, a la idea de libros de viajes, de acuerdo con el modelo clásico aunque remoto de los Viajes de Marco Polo, que según Pérez Priego: «va descubriendo los distintos lugares, pero sin unirlos, al armazón de un itinerario» ${ }^{2}$ También siguen esta idea libros como Twilight in Italy de D. H. Lawrence, muchos de los Cua-

${ }^{1}$ Idoia Arbillaga: Estética y teoría del libro de viaje. El 'viaje a Italia' en España, Málaga, Analecta Malacitana, 2005, p. 94.

${ }^{2}$ Pérez Priego, M. A.: «Estudios literarios de los libros de viajes medievales», Epos, 1 (1984), pp. 220-221. 
dros de viaje de Heine, la Venice de Joseph E. Morris, etc. I. Arbillaga insiste en que la «presentación directa de las ciudades o localidades, produciéndose por tanto una elipsis de los trayectos intermedios $»^{3}$, no impide de ninguna manera que puedan seguir siendo tenidas por libros de viajes.

Este conjunto de narraciones se marcan dentro de una tradición de libros de viajes, probados en la literatura catalana, como poco y según las monografías existentes ${ }^{4}$, desde los siglos XIV y XV, con textos principalmente dedicados a viajes a Tierra Santa, como es de Guillem de Treps, Viatge a Terra Santa (1323), destino que continuará prevaleciendo durante los años de Decadència. En el tránsito de los siglos XIX al XX se inicia una época de esplendor de dicho género que abarca desde el texto canónico de Jacint Verdaguer, Dietari d'un pelegrí a Terra Santa (1889) hasta textos referenciales como los de Josep Pla, de cuyo corpus recuperaremos el título que nos traslada a Italia, Cartes d'Itàlia, compendio así mismo de crónicas periodísticas.

De Ramon Vilaró i Guillemí, autor de estas crónicas viajeras, tenemos pocos datos biográficos, aunque nuestras pesquisas nos han permitido encontrar algún dato que podría ser de interés, más allá de los que ya eran conocidos 5 . Podemos destacar que fue un personaje conocido dentro de la vida literaria catalana de principios del siglo veinte. No sólo celebró una tertulia literaria en su casa, Can Vilaróo, sino que también llevó a cabo la publicación de una serie siete fascículos con contenido poético ${ }^{7}$ - a parte de nombres menores, con firmas que van de Joaquim Ruyra, Víctor Català, Apel-les Mestres, Ignasi Iglesias o Santiago Rusiñol a Josep M. de Sagarra o Ferran Soldevila y hasta J. M. López-Pico o Carles Salvador, es decir del Modernismo a los años de la vanguardia-, así como rubricó, de acuerdo con el material hasta hoy rescatado una producción periodística en la revista anteriormente citada, compuesta tanto por esta serie de «notes de viatges» como por sus crónicas teatrales enviadas desde Italia.

\section{LOS RELATOS}

Un posible ordenamiento interno de los relatos. Sobre las citadas columnas periodísticas, podríamos trazar un itinerario geográfico a partir de las referencias a las ciudades visitadas. No obstante somos del parecer de que no seria coherente por nuestra parte basarnos en esta idea para realizar nuestra investigación, por-

${ }^{3}$ Idoia Arbillaga, ed. cit., p. 64

${ }^{4}$ Véase Diccionari de la literatura catalana, Barcelona, Edicions 62, 1979.

${ }_{5}^{5}$ Véase Història de la Literatura Catalana. Vol. VIII, Barcelona, Ariel, p. 405; el autor no aparece recogido en el $N D 62 L C$, dir. E. Bou, 2000.

${ }^{6}$ Para un mayor conocimiento de los participantes en dicha reunión, véase la tesis de Jordi Lladó i Vilaseca, Ramon Vinyes i el teatre (1904-1939), tesis doctoral dirigida por Jordi Castellanos i Vila, Universitat de Barcelona, 2002, pp. 214 y ss.

7 Entre 1926 y 1932, por las informaciones que manejamos, Vilaró publicó «El Ventall del poeta», antología poética de autores catalanes; se puede consultar en la web del Aula Màrius Torrès (http://www.aulamariustorres.org/materials/hemeroteca/EVdP/web/index.php), consultada el día 8 de julio de 2008. 
que caeríamos en un error, ya que hay que advertir que estas crónicas no corresponden a un solo viaje sino a varios. No poseemos indicativos reales del viaje de una ciudad donde se desarrolla a otra, aunque si existe algún ejemplo en ciertas «notes de viatge» acerca del traslado de una ciudad a otra. El género no requiere que se traslade a la obra la absoluta totalidad de la información concerniente a los desplazamientos internos por el país o la región visitada.

Por lo tanto, los textos representan un itinerario parcial ya que en ellos no aparece una indicación clara que indique la conexión entre uno u otro, según el esquema planteado por I. Arbillaga, permitiéndole al autor ese rasgo una mayor flexibilidad en la construcción de la obra literaria ${ }^{8}$. Aún así y de acuerdo con lo advertido, del desplazamiento de una ciudad, donde transcurren las historias, a otra, si encontramos algún ejemplo:

Deixo Venecia per a anar a Rimini, sempre a la vora de l'Adriàtic, aquest mar tant bell com rondinaire ${ }^{9}$

A pesar de ello, a nuestro parecer, el mejor ordenamiento de los textos sería partiendo del análisis textual, pudiendo agruparlos en dos conjuntos. Un primer grupo que denominaremos como literatura de viaje, ya que en estas peculiares crónicas, caracterizadas por su brevedad y condensación, encontramos rasgos de alcance literario dan coherencia a este conjunto de colaboraciones:

a) un recorrido geográfico: nos marca los lugares por los cuales debe pasar el tren, vehiculo utilizado en los desplazamientos, para llegar desde Cataluña hasta Italia. Por ejemplo, en los textos encontramos descripciones de algunas ciudades francesas durante la guerra, por lo cual se añaden descripciones de alcance psicológico o sensitivo:

Cannes, Nice, Montecarlo, semblen ciutats mortes: l'encís que teníen per a l'assedegat d'amor, de jòc o d'espiritualitats artístiques, s'ha esvait.

El gran món francès no hi és i per llurs estacions hi van passant avui la llitera de ferits, com ahir la passaven les dames elegantíssimament abillades i els cavallers amb el frac de rigurosa etiqueta. ${ }^{10}$

Les ciutats (...) no indiquen el més lleu malestar per causa de la guerra; totes treballen, per tot l'animació regna senyora i és perque els fills de l'Italia consideren els moments actuals com un mal menor i necessari pel seu viure; lluiten resolts com si tinguessin la victoria per descontada i si els parles de sacrificis la seva cara s'il-lumina, amb el to de llurs paraules, et trasbalcen i penses que un poble com aquest sabrà vèncer al seu etern enemic. ${ }^{11}$

\footnotetext{
${ }^{8}$ Véase Idoia Arbillaga en Estética y teoría del libro de viaje. El 'viaje a Italia' en España, p. 73.

9 «Notes de viatge. O'Marenà», El Teatre Català. 95, p. 878. A partir de este momento, haremos referencia a los textos de la manera siguiente. Primero aparecerá las siglas de la revista (ETC), el número que corresponde al fascículo y por último la página.

10 «Notes de viatge. Passant la França», ETC, 141, p. 729.

11 «Notes al vol, d'un viatge en temps de guerra», ETC, 198, pp. 804-805.
} 
b) un viaje en el tiempo: circunstancias temporales de sus viajes a Italia, que reflejan la I Guerra Mundial en los textos:

Em trovo en un país a on no't pots girar que no vegis uniformes de tota mena; militars al carrer, al cafè, al teatre, als hotels, en fi, per tot; i no dic rès dels trens, perque, aquets, n'estàn invadits; del soldat ras al general tots tenen dret a seure al primer lloc que troven, i degut an això, a lo millor te trobes tan rodejat de tropa que no sembla sinó que estiguis en un quartel ${ }^{12}$

El segundo grupo estaría formado por crónicas de viajes, tal vez en el sentido más estricto del concepto. Aquí los textos comparten características, indicios y signos del género, y principalmente retratan tipos de personajes o describen ciudades. A su vez lo podríamos dividir en dos subgrupos, aunque, no obstante, este presente esquema puede funcionar cruzadamente, ya que cualquiera de los rasgos aquí elegidos para ordenar los textos los podemos encontrar también en la otra serie:

a) el primer subgrupo se centraría en mayor medida en retratar tipos de personajes, aunque encontramos al mismo tiempo alguna referencia a las ciudades italianas que visita el viajero.

b) el segundo, presenta una mayor referencia a las ciudades italianas, como se puede comprobar en la descripción de Rimini:

Rimini és una de les ciutats més boniques de l'Adriàtic; senyorejant molt a l'estiu, arribant a la tardor es queda orfe dels forasters que durant la temporada de banys l'invadeixen, i, fòra aquest element de vida, l'aspecte de poble trist i quiet que pren la ciutat plana damunt dels séus habitants d'una manera extraordianaria. ${ }^{13}$

El viaje. Nuestro viajero utiliza principalmente el tren para realizar sus desplazamientos a través de tierras italianas cuando tiene que recorrer largas distancias. Era medio de transporte muy empleado a principios del siglo veinte, gracias a su novedad técnica y por la reducción en el tiempo invertido en el traslado de una ciudad a otra. Realmente el transporte proporciona el primer factor de conocimiento de un espacio extraño por parte del viajante, pues desde luego no es lo mismo ir a pie que en coche o viajar en avión ${ }^{14}$. El transporte determina la relación del viajero con el paisaje y las impresiones estéticas que éstos reciben; como se puede comprobar, nuestro autor, que ya nos había descrito su salida de Venecia en texto anteriormente citado ${ }^{15}$, da la siguiente referencia de su recorrido por la isla de Sicilia:

12 «Notes al vol, d'un viatge en temps de guerra. El pobre mut», ETC, 199, p. 825.

13 «Notes de viatge. En Piccini», ETC, 105, p. 149.

14 A. M. Machado y A. H. Pageaux, «As experiências da viagem» en Da literatura comparada à teoria da literatura, Lisboa, Fundamentos, 2001, pp. 33-47.

${ }^{15}$ Véase la cita de la nota 9. 
Al pujar al tren que'ns havía de portar a Catania, la confusió fou enorme, ja que tothom volía agafar el millor lloc i anar còmodament darrera les finestretes, per a gaudir de l'espectacle incomparable que ofereix tota la costa de la Sicilia, plena de panorames a quin més bell, i que deixen, al qui té la sort de contemplar-los, una impressió inesborrable. ${ }^{16}$

Pero también encontramos otro ejemplo de medio de transporte, es el caso de un viaje en carruaje de caballos, donde observamos una visión distinta del paisaje:

A la porta de l'hotel ens esperava un cotxe que, una vegada nosaltres dintre, emprengué una cursa rapidísima cap el lloc a on el meu amic havía ja indicat previament.

Durant el cami jo no tenía ni esma de parlar; pel meu cap passaven un munt de idees que tot em trasbalsaven, i ni el paisatje meravellós dels Alps nevats i plens d'irisacions enlluernadores, podía imposar en el meu esperit la serenitat que tant necessaria em sería. ${ }^{17}$

El transporte es, por otra parte, uno de los medios en los que el viajero-escritor se relaciona con los individuos del país, conoce a otros viajeros o se pone al día en sus lecturas acerca del lugar visitado. En nuestro caso poseemos muchos ejemplos para estas relaciones personales entre los viajeros, como podremos ver más adelante cuando tratemos precisamente sobre los compañeros de viajes, figuras a las que nos acercaremos posteriormente.

Descripción de las ciudades visitadas. El discurso empleado para estas «Notes de viatge» no es el específico que encontraríamos en los libros de viaje. No tenemos un gran discurso descriptivo ni tampoco ningún ejemplo de discurso narrativo. Lo que hallamos en gran medida es un incipiente análisis psicológico de los personajes, o un retrato que, como hemos señalado, veremos más adelante.

Los escasos ejemplos de discurso descriptivo que descubrimos en estas crónicas son fundamentalmente con ocasión de las ciudades visitadas. La descripción la utiliza el autor como elemento de introducción para el verdadero fin de la crónica, el ya advertido y minucioso desarrollo psicológico de los personajes que construye mediante el diálogo a partir de las impresiones de su interlocutor.

En las crónicas en las que encontramos pequeñas pinceladas sobre la geografía urbana, hallamos primero descripciones generales de las ciudades sin entrar mucho en el detalle; en algunas de ellas, más que la descripción física del espacio, se describen los sentimientos personales que se tienen cuando se llega a esas ciudades. Así puede ser el ejemplo anterior sobre Rimini ${ }^{18}$ o el siguiente sobre Torino:

\footnotetext{
16 «Notes de viatge. La noia rossa», ETC, 100, p. 54.

17 «Notes de viatge. Desconsol», ETC, 185, p. 598.

18 Véase la cita de la nota 13.
} 
Torino (...) anem caminant pel deliciós Corso Vittorio i, (...) tan polida i altraienta, tant exquisida i plena d'encisos com podría ésser la Barcelona dels meus somnis, la ciutat de les meves il-lusions, records i esperances! ${ }^{19}$

En otras ocasiones, también es cierto, sí encontramos descripciones físicas de las ciudades. El caso más claro lo constituyen las líneas dedicas a Messina. Se describe una ciudad en ruinas tras el terremoto que ha sufrido el sur de Italia. Las descripciones más crudas son las que aparecen en «Notes de viatges. Passionaria», presentando una ciudad muerta según revela la impresión sufrida por el viajero:

...Messina era encara una tomba oberta que no's cansava d'engolir cadavres i més cadavres.

El foraster que arribava de bell nou, mig aclucava els ulls per a no veure aquell quadre espantós, impossible de descriure amb tota sa esgarrifosa veritat. $^{20}$

...vaig endinzar-me en aquell immens cementeri, caminant entre runes, sentint la bafarada de tota una ciutat descomponent-se i veient com, a cada pas, un agrupament de persones, fent rollo, contemplaven als empleats de l'Estat com desenterraven troços de persones i com ajudats d'algú que va sobreviure an aquella tragedia, feien els posibles per a identificar-los. ${ }^{21}$

Por su parte, las descripciones en «Notes de viatge. Una nit a Messina» no resultan tan dramáticas como las anteriores; están más suavizadas, se habla de una ciudad viva, que está recuperando su actividad:

...però ara Messina ja no és morta; ho semblava que ja mai més existiría, després de la catàstrofe i que la pau regnaría per sempre més damunt d'aquelles rúnes que tantes tragedies amaguen: pero ca!

Es viva la ciutat joiell de la Sicilia, te vida exuberant, cor que palpita i una ànima que se't fa séu tant bon punt els teus peus caminen per aquells carrers que oscilant d'entant entant, sembla que sigan gronxats pel dolç va-i-ve de les onades! $!^{22}$

También encontramos descripciones que se centran en diferentes espacios que podemos visitar en cualquier ciudad; es decir, una plaza, una casa, un teatro... En «Notes de viatge. En Piccini», hallamos la descripción de la plaza de Rimini:

Solament la plaça m'interessava, tant bonica, tant plena de records i amb aquella patina de velluria que tanta simpatia inspira.

\footnotetext{
19 «Notes de viatge. Desconsol», ETC, 185, p. 595.

20 «Notes de viatge. Passionaria», ETC, 117, p. 340.

21 «Notes de viatge. Passionaria», ETC, 117, p. 340.

22 «Notes de viatge. Una nit a Messina», ETC, 145, p. 787.
} 
Tota ella voltada de porxos desiguals, sembla una colossal cadena ont cada generació hi hagués afegint una anella, fins a trobar el gegantí rellotge, les campanes del qual feien estremir de goig a la cèlebre Francesca cada vegada que amb el séu sò harmoniós li senyalaven l'hora de l'amor, el moment desitjat, que ella esperava amb deliri, tot repetint baix, baixet i amb por de descobrir-se, «Ara..., ara!...» ${ }^{23}$

En «Notes de viatge. Desconsol» tenemos la descripción de una prisión que sorprende por su aspecto, tratándose, tal vez, de un edificio monumental reconvertido en sus funciones:

L'immens edifici, voltat de jardins, ho sembla tot menys una presó (...)

Ens endinzàrem en l'edifici i a l'intentar passar una segona porta, que donava entrada en un magnífic pati de pur istil piamontés, un dependent prengué les flors que duia el meu amic (...)

L'estança a on ens havía fet entrar no tenía cap aspecte de presó, però a mí em queia al damunt d'una manera espantosa. ${ }^{24}$

Sí en Messina teníamos dos visiones de la ciudad, una en ruinas y otra en reconstrucción, ese doble aspecto también se observa en la referencia a algunos de sus edificios, como es el caso de las viviendas. Véase por ejemplo, «Notes de viatge. Passionaria», la descripción de una casa en ruinas:

Prop de lo que fou la Catedral, joia inapreciable de l'art italià, les parets mestres d'una casa s'aguantaven encara dretes; no hi havía pisos perquè la muntanya de runa arribava fins al segón; però, en el que fou el terç, encavalladament, unes vigues que no havíen volgut cedir a la força del terratrèmol, sosteníen les desferres d'un llit, aguantat allí com per miracle. An el capçal d'aquell llit, que semblava guardar encara l'escalforeta dels qui en foren llençats quan el terrible instant, hi havía un Crist clavat en creu que amb els braços estesos, talment hauríeu dit que feia acció d'anar a abraçar tota aquella allau d'horrors! ${ }^{25}$

En «Notes de viatge. Una nit a Messina», como ya hemos dicho, la visión es más optimista. Destacaremos la descripción de un teatro. Hay que recordar que estas narraciones están publicadas en una revista especializada en teatro, y por eso alguna de las referencias que aparecen se da por conocidas por el lector:

Figuréus una barraca com mig Soriano, en la qual, contre les ordres guvernatives, hi ha un primer pis amb lotjes que semblen talment una serie de camarots arrenglerats amb perill de caure damunt del públic del pati.

23 «Notes de viatge. En Piccini», ETC, 105, p. 150.

24 «Notes de viatges. Desconsol», ETC, 185, p. 598.

25 «Notes de viatge. Passionaria», ETC, 117, p. 340. 
Aquest el formen tres departaments: en tots tres tenen entrada els militars, (...) En els dos departaments principals, les cadires son de boga, d'aquelles que sembla que'n tinguin més al cap que el peus: encara no les mous ja cauen i no sembla sino que siguin fetes a prova de terratremol; a l'altre departament uns bancs de fusta pintada d'un vert de banc de canti que esparvera, serveixen de seient al distingit públic que hi concorre. ${ }^{26}$

Por último vamos a hacer referencia a una ciudad italiana que todavía no hemos citado. Nos referimos a Padova, en «Notes de viatge. La cega». En esta ocasión, Vilaró describe la ciudad a través de la comparación con Venecia, urbe que también es visitada por este viajero y reflejada en otras columnas, pero sin mostrarnos en ellas descripciones de sus plazas y edificios más representativos.

Como hemos mencionado a lo largo de estas líneas, volvemos a encontrar los dos tipos de descripción utilizados en otras narraciones, es decir, una descripción general y una especifica. La general describe la ciudad a través de los sentimientos:

La vella ciutat de Padova és l'avant-sala de Venezia: sempre curulla de forasters, porta en son si un no sé què que atrau: sense ser Venezia, hi somníes, i sense tenir l'aire de gran ciutat, hi sents tots els batecs d'una ànima ciutadana, alegre, bulliciosa, que's mou de mil maneres, acaronan-te amablement, fen-te oblidar la quietut de Venezia si ja'n tornes, o fen-te presentir l'encís dels vells canals, les dolces cançons dels gondolieri i la meravellosa visió de la Plaça de Sant Marc al migdia, si encara no has tingut la sort d'estar a la perla de l'Adriàtic, a Venezia, la ciutat única, la lluminosa, la que't fa penar, si de nit hi entres, la que fa eixir de ton pit exclamacions de joia mai somniades, quan al matí se t'ofereix radiant de sol i de belleses, i la que't fa plorar quan, al marxar dintre la góndola, la vas deixant... deixant, i ni esma tens de donar-li l'arreveure!

Padova és l'avençada de tot això, i els séus carrers, tots enfilerats de porxcs ${ }^{27}$, donen l'impressió d'uns canals secs, sense l'alegría de les góndoles ni l'espill de l'aigua, que't sembla, a Venezia, quan t'hi esguardes, tenir el cel a tocar, la gloria arràn, arràn de llavis! ${ }^{28}$

La específica, por su parte, se centra en la descripción de la Basílica de San Antonio, con particular atención a la capilla:

...una atracció immensa, un encís insuperable: la Basílica de Sant Antoni, ont són guardats, en una sumptuosa tomba de marbres, els restes del Sant portugès.Aquesta Basílica, quals cúpules recorden vagament les de Sant Marc de Venezia, no està acabada; tant sols la capella del Sant, que és un veritable joiell d'art i de riquesa, brilla continuament en la foscor del reste de l'iglesia. En aquella capella s'aboca tota la cera, tots els diners dels creients que a corrúa

\footnotetext{
26 «Notes de viatge. Una nit a Messina», ETC, 145, p. 788.

${ }^{27}$ Error tipográfico, seguramente sería porxos.

28 «Notes de viatge. La cega», ETC, 126, p. 486.
} 
feta compareixen davant del Sant a pregar per a que faci el miracle de curar llurs nafres. ${ }^{29}$

Los compañeros de viaje. El desarrollo psicológico de los personajes lo consigue, como ya hemos anunciado con anterioridad, mediante el diálogo y las impresiones que recibe de su interlocutor. En todos los personajes que el autor describe en sus narraciones, se fija en ellos por una característica física o de su personalidad que sirve de motivo para entablar una conversación.

A su vez podemos dividir estos personajes descritos en dos grupos: el primero lo forman aquellos que están relacionados con el medio de transporte que utiliza en sus desplazamientos por Italia, el tren; y el segundo, aquellos que describe durante su estancia en las ciudades. Todos tienen una característica en común, que le llama la atención a Vilaró; son personajes desgraciados, por la guerra o por el rechazo de la sociedad. Pero, dentro de la desgracia, hay diferentes maneras de vivir con ella. Esta lucha es otro elemento de enfrentamiento de estereotipos, que nos va ayudar en el análisis.

El primer bloque de personajes que vamos a perfilar, es el de los relacionados con el tren. En este caso, reconocemos tres parejas: los soldados, la dicotomía mar/tierra y los personajes femeninos jóvenes.

En estas crónicas, al ser escritas durante el viaje y en el tiempo de guerra que vive la sociedad europea, y en especial a la italiana, encontramos ejemplos y referencias a los soldados que debían plagar las ciudades y los trenes, como compañeros de viajes. La primera visión que tendrían los viajeros que cruzaran la frontera española con la francesa, o llegaran a Italia, seria la de los soldados marchando al frente o de regreso a su patria:

Anaven d'una manera que feia pietat: bruts, espellifats, amb les sabates plenes de fang i el kepis tant destenyit, que ni color definit tenía: semblava que tornaven de guerra $\mathrm{i}$ en canvi...

Un oficial anava per tots els vagons enquibint aquell remat d'homes destinats al sacrifici: els uns, contents, semblava que no's donaven compte de lo anaven a fer, mentres els altres, els més pocs, amb la mirada perduda $\mathrm{i}$ amb posat de resignació, guardaven un silenci imposant. ${ }^{30}$

La França és un formiguer de soldats: aquí en marxen plens de salut, vermells com el color de la sang que van a llençar per la patria; allà, en canvi, n'arriben de demacrats, grocs, amb els ulls embeguts conques endins, com si es cerquessin la materialitat de l'ànima que han deixat encara lluitant per l'independencia de la França!

Ranquejant els uns amb els braços inutilitzats els altres i portats en lliteres els més, els quals van enquibint dintre els trens i distribuint-los per tot el país. $^{31}$

\footnotetext{
29 «Notes de viatge. La cega», ETC, 126, p. 486.

30 «Notes de viatge. Passant la França», ETC, 141, p. 728.

31 «Notes de viatge. Passant la França», ETC, 141, pp. 728-729.
} 
Estos dos ejemplos nos dan una visión general de la realidad europea de aquella década y, con las descripciones de las ciudades anteriormente reseñadas, nos vuelve a la realidad y a la crudeza de la vida.

Muestro cronista no se fija a la hora de presentarnos a aquellos personajes en su alegría, aunque la exterioricen, sino que parece preferir aquellos, como ya hemos reseñado, que tienen un rasgo o un problema que conmueva y provoque ternura o tristeza. En el caso de los soldados son las heridas y cómo estos afrontan su invalidez. Tenemos dos ejemplos de soldados, que pasamos a revisar. Estos dos regresan a sus casas con actitudes diferentes, como se observa a través de las descripciones o por las conversaciones con el autor de las correspondientes columnas. En el caso del soldado protagonista de «Notes al vol, d'un viatge en temps de guerra. El pobre mut», el protagonista viene rodeado de compañeros heridos, intentando pasar lo mejor posible el viaje:

Tots set eren ferits que veníen del front, d'allà als cims desl Alps a on, entre'ls gels i la inclemencia del temps la joventut italiana lluita coratjosament, heroicament, per la lliberació de les terres germanes.

Entre'ls meus companys de viatge un n'hi havía que, en veritat dec dir, no parlava que no fés riure, i val a dir també que parlà tant, que no parà en tota la nit.

Ell no reia mai, intervenía en la conversa general, hi deia el seu xisto i amb satisfacció de veure-se'l celebrat, esperava el moment oportú per a deixar anar l'altre ${ }^{32}$

En el caso del descrito en «Notes de viatge. L'Invalid», el protagonista regresa en solitario y la primera impresión que se tiene de él es a través de la soledad que proyecta:

Per fi el conductor que m'acompanyava m'indicà un petit departament ont no més hi havia un ferit, ocupant, estirat, tots els quatre seients d'un cantó..$^{33}$

Otra diferencia que hemos observado es a través de las conversaciones con estos dos soldados, donde se nos revela que el invàlid procede de una familia acomodada que le permitió estudiar una carrera y casarse joven, pero a quien la guerra truncó todas sus expectativas de vida en familia; mientras el pobre mut, por otra parte, es originario de una familia humilde y desestructurada, obligándole el padre en la niñez a mendigar:

... Il grande mazcalzone em feia anar a demanar caritat, descalç, espellifat, plè de miseria i amb el cap plè de polls, i quan erem al carrer, vigilnat-me, em deia:

- Apa ragazzo, a pidolar, però signant ho no més que demanes almoina: tocant als passants, estirant-los-hi la roba, que aixís, veient-te tan aprop, per allunyar-te d'ells te'n faràn. ${ }^{34}$

\footnotetext{
32 «Notes al vol, d'un viatge en temps de guerra. El pobre mut», ETC, 199, p. 825.

33 «Notes de viatge. L'Invalid», ETC, 107, p. 183.

34 «Notes al vol, d'un viatge en temps de guerra. El pobre mut», ETC, 199, p. 826.
} 
El invàlid, por todas estas circunstancias, no lleva muy bien la pérdida de un brazo y la invalidez del otro por culpa de una bala. Durante la conversación, éste expresa sus continuas preocupaciones sobre cómo va a encarar su nueva vida con su familia:

— Calleu, per pietat (...) res de lo que dieu pot ser; no'n tinc de cura, sabeu?, no'n tinc de cura; m'ho diuen els metges amb els seus diagnòstics, m'ho dic jo, per què sé com me trobo, m'ho diu tot lo que'm volta i fins m'ho diu vós, amic, deixeu que us ho digui amic, perquè d'ençà que us tinc al davant no feu sinó mirar-me amb llàstima i prodigar-me tots els afalacs, com si ja de temps ens coneguéssim!

\section{(...)}

No'n tinc de pares, i si bé tinc ja formada una familia, còm la trobarè ara? Com arribaré a bastir la plena felicitat d'un fill a qui encara no conec, sense ri els braços per a poder-lo abraçar! ${ }^{35}$

Y el último tiro de gracia que le da esta vida es a su llegada a Nápoles, cuando se encuentra con su mujer, anteriormente descrita con tremenda pasión $^{36}$, enterándose entonces de la pérdida del hijo:

—Il bimbo, il bimbo! — digué tot de sobte aquell desgraciat, frisós per veure el fruit del séu amor, però la seva dòna, al sentir aquells mots aixecà el cap, fixà son esguard en el del marit com volent-li dir quelcom que li cremava l'ànima, i es llençà damunt els coixins del tren plorant amargament, com sols pot plorar una mare!

El pobre ferit comprengué tot el significat d'aquella mirada i d'aquell plor; semblà com si tot el món li hagués caigut en un moment a sobre, i abaixant la testa, resignadament, damunt son pit, murmurà entre dents:

— Desventurats de nosaltres ${ }^{37}$

Por contra, el pobre mut, a pesar de su niñez de pobreza y miseria ya recordada, cuando se da cuenta, en su juventud, de que esa vida no era para él, rompe con todo ese mundo e inicia una nueva existencia. A pesar de sus heridas, no ve truncada su felicidad, que había expresado al autor a través de los chistes:

...callava per propia voluntat, em semblava que callant deia més coses, $\mathrm{i}$ tant era aixís, que'l dia que la llum de la raó il-luminà el meu cervell i vaig comprendre que era explotat per un miserable, no'm fou possible, al despedir-me d'ell, dir-li més que una paraula: lladre! ${ }^{38}$

35 «Notes de viatge. L'Invalid», ETC, 107, p. 184.

${ }^{36}$ Esta descripción la encontramos en la página 183.

37 «Notes de viatge. L'Invalid», ETC, 107, p. 185.

38 «Notes al vol, d'un viatge en temps de guerra. El pobre mut», ETC, 199, pp. 826-827. 
Otra de las parejas que estamos analizando la hemos denominado dicotomía tierra/mar. Está representada por los personajes del marinero y del guarda agujas. Como el resto, son desgraciados. Su desventura es la soledad y viene marcada por el ansia de conocer como se encuentra su familia. La soledad del marinero está provocada por encontrarse en tierra, y no conocer lo que está ocurriendo durante el nacimiento de su hijo, avisándole su padre que el parto va mal. Esto le incita una continua ansiedad y, desubicado en un medio que no es el suyo, lo llama immonda caixa, como se refleja en las continuas anotaciones de Vilaró sobre el marinero, por ejemplo:

Em fa gracia un mariner tancat dintre el tren, i surto jo també al passadiç a estirar les cames i a veure si agafo conversa amb aquell presoner $^{39}$

...el mar (...), malhumorat, sembla acompanyar-lo en sa desgracia, aquell mar ont ell tant tranquil estava fins que la dolorosa noticia l'ha fet posar en camí, és cosa massa cosa per a mi $!^{40}$

Como moraleja, otro personaje, sin mayor relevancia que ser madre también de marinero y coincidiendo con una situación parecida, sentencia que:

—No li parleu mai, a cap mariner, dintre el tren, perquè són gent que quan s'hi fiquen és per una desgracia que'ls passa i encomanen el séu mal als qui els rodegen. ${ }^{41}$

La soledad del guarda agujas es la de encontrarse ya solo en la vida y sentirse olvidado, no por sus seres queridos, sino por el Estado, como podemos comprobar a través de las siguientes palabras:

L'Estat (...) ens té aquí durant anys i anys mateix que besties; lluny de tota civilització, com no siga aquella que passa de llarc i que veiem solament dintre els vagons; menjant i dormint malament, perquè el guany no arriba per viure, ens anem morint de miseria damunt d'aquesta terra tant ingrata; vivim com espectres i quan aturem an algú, com suara he fet amb vós, s'aparta de nosaltres amb repugnancia; ... ${ }^{42}$

También toda esta soledad está provocada por el espacio físico que le rodea, como ya ha quedado reflejado en la cita anterior o podemos leer en la siguiente:

...terra aont, (...), no trobes cap arbre que't faci la caritat, d'una ombra ni el rajolí d'una font que't convidi a apagar la sed i a sentir la dolça remor de l'aigua quan estimbant-se penyals avall sembla que canti una cançó que no ha de tenir fi, per anys que passin! ${ }^{43}$

\footnotetext{
39 «Notes de viatge. O'Marenà», ETC, 95, p. 878.

40 «Notes de viatge. O'Marenà», ETC, 95, p. 879.

41 «Notes de viatge. O'Marenà», ETC, 95, p. 879.

2 «Notes de viatge. El guarda agulles», ETC, 111, p. 262.

43 «Notes de viatge. El guarda agulles», ETC, 111. p. 261.
} 
Todo ello le ha creado un malhumor que se le ha agudizado por la pérdida de la familia. La única cosa que le calma y que provoca ternura en su interlocutor, es cuando habla del amor a su mujer, otra persona doblemente desgraciada dentro de una sociedad que no se preocupa de los pobres ni por sus propios camaradas de pobreza. Habla en unos términos que advierte como, dentro de lo feo, triunfa lo bello ${ }^{44}$. De ese amor nace un hijo, al cual intenta enseñar que huya de ese mundo donde se había criado su padre: «...jo li inculcava l'idea de fugir d'aquest exil, de volar com un aucell, ell que ja hi sabia cantar!» ${ }^{45}$. Pero la única salida que tiene el hijo es la de ser bandolero. La muerte del hijo desencadena la muerte de la mujer, intensificando la soledad del guarda agujas, así como la rabia, además, contra la humanidad. Este sentimiento provoca el descarrilamiento del tren ${ }^{46}$.

La última pareja de compañeros de viaje que analizaremos es la de los personajes femeninos jóvenes. La diferencia entre estos dos personajes es la de su condición social. Teresa («Notes de viatge. La noia rossa», ETC, 136) es hija de un rico terrateniente, está enferma y marcha a Sicilia a recuperarse. Por otra parte, Giannina («Notes de viatge. La noia gran», ETC, 100) es de procedencia humilde y marcha a Génova en búsqueda de una mejor fortuna, tras la muerte de su padre y su hermano por culpa de la guerra. Teresa está descripta desde sus problemas físicos y esa es la primera impresión que tenemos de ella en el tren, como estatua de «ivori», «les venes d'aquell cos decandit s'omplissin de sang i donguessin un xic de vida als llavis amoratats de la noia rossa $»^{47}$; a Giannina, por su parte, la describe también marcada por su desgracia, pues «les seves faccions anaven prenent una expressió de tristesa que feia llàstima» ${ }^{48}$. Tenemos una tercera descripción, que se enfrenta con estas dos, la de una muchacha joven siciliana, que es mucho más alegre:

Bella Nostra de la terra siciliana. Bruna de pell, cabells negres i d'ulls magnífics. D'ont havía sortit aquella bellesa a fer escarni a la pobre noia rossa i blanca que se la mirava amb por i vergonya a la vegada?

Com una nova samaritana, recolzada arràn del pou, semblava fer ostentació de la seva magnífica figura, i si de la seva cara el pintor més enamorat de lo bell n'hauría tret model per a fer una obra excelsa, en el séus posats i en la seva carn palpitanta l'escultor hauría trobat l'inspiració per fer la seva obra definitiva.

Era la dòna siciliana pura de linies i de mirar enfellonidor, tal com surt de les aspres muntanyes d'aquella terra incomparable. ${ }^{49}$

En cuanto a los personajes ciudadanos podemos analizar dos parejas respectivamente de personajes femeninos y masculinos. Los femeninos que son re-

\footnotetext{
44 «Notes de viatge. El guarda agulles», ETC, 111, p. 262.

45 «Notes de viatge. El guarda agulles», ETC, 114, p. 294.

46 «Notes de viatge. El guarda agulles», ETC, 114, p. 295.

47 «Notes de viatge. La noia rossa», ETC, 136, p. 54

«Notes de viatge. La noia gran», ETC, 100, p. 649.

«Notes de viatge. La noia rossa», ETC, 136, p. 55.
} 
tratados en la ciudad, son personas mayores que se encuentran inmersas en la mendicidad. El personaje de la narración de «Notes de viatge. Passionaria» $(E T C, 117)$ se encuentra en estas circunstancias por causa del terremoto sufrido en Messina y por las escasas ayudas recibidas del gobierno italiano ${ }^{50}$. En el caso de la povera Anna, personaje de «Notes de viatge. La cega» $(E T C, 126)$, es a causa de un accidente con una caldera en el cual también muere su marido. Son personajes que, por su edad o por sus malformaciones físicas tras el accidente, no son ya bellos cuando son descritos. Así se describe a Anna:

...Les seves faccions degueren sofrir les més horribles de les cremades, perquè
la llur deformació era tant terrible, que el meu primer instint va ésser girar la
vista per a no veure-les. Amb els ulls desmesuradament oberts, semblava voler
endevinar la meva fesomía, i jo, al sentir la força d'aquell mirar al damunt, ni
esma tenía d'apartar els ulls d'aquelles nines tant rojes, tant de color de sang,
que a l'intentar alçar-se per a esguardar-me, queien altre cop pesadament con-
ques avall, com un sol que va a la posta! ${ }^{51}$

A su vez, estos dos personajes femeninos, se encuentran enfrentados a las descripciones de sus hijas, por su juventud. A la Passionaria la describe como «pobre noia com si no fós d'aquest món $»^{52}$ y a su hija:

...sense res al cap, fins a les espatlles li queien els cabells, rossos com una garba de blat, i els séus ulls bellugadiços teníen un aire d'intel-ligencia que encisava: còm era bonica! ${ }^{53}$

Estas dos mujeres afrontan la precariedad de su vida de forma diferente. La Passionaria se aferra a lo perdido, su familia y su casa ${ }^{54}$, no quiere de ninguna forma rehacer su vida y critica muy duramente a los ciudadanos de Messina que están recuperando una nueva ciudad ${ }^{55}$. Anna, en su caso, se aferra a la religión y a su devoción a San Antonio, que le lleva incluso a ver visiones del santo y a entrar en interacción con él:

...No vaig tenir altre camí que el del Sant, ni altra porta oberta que m'oferís aixoplug; (...) al traspassar aquesta portalada, va semblar-me que, recobrant la vista, veia al Sant alçar la seva destra per a beneir-me i com si una veu que devallés del cel em digués: queda't! Vaig creure-la, i resant m'estava, en un èxtasis quasi diví, quan vaig sentir que una mà posava entre les meves unes monedes que eren més fredes que'l glaç... oh, Déu!, vaig pensar, és la primera caritat, el primer moç de pa que guanyo per a la meva filla, l'únic raig de claror que veuré en la nit inacabable que m'ha d'acompanyar a la nit tomba! ${ }^{56}$

\footnotetext{
50 «Notes de viatge. Passionaria», ETC, 117, p. 324.

51 «Notes de viatge. La cega», ETC, 126, p. 487.

52 «Notes de viatge. Passionaria», ETC, 117, pp. 341.

53 «Notes de viatge. Passionaria», ETC, 117, p. 340.

54 Recuérdese la descripción de la casa derruida anteriormente, véase la cita de la nota 25.

55 «Notes de viatge. Passionaria», ETC, 117, pp. 341.

56 «Notes de viatge. La cega», ETC, 126, p. 487
} 
Los últimos personajes que vamos a recuperar son de clases sociales diferentes, ambos muy relacionados con nuestro autor, el mundo del comercio, con el cual se gana la vida, y el mundo de la bohemia o del teatro, una de sus pasiones por los pocos datos biográficos que conocemos. El mundo del teatro se refleja en la mencionada narración «Notes de viatge. Una nit a Messina» ${ }^{57}$, pero realmente lo que le interesa para sus narraciones es el teatro callejero.

Por lo tanto estos personajes son jóvenes que se caracterizan, o por un rasgo de alegría, en dos casos, que se desprende de las narraciones; o, el otro, por la desgracia de encontrarse en la cárcel, por el asesinato de un hombre por cuestiones de honor. El personaje de «Notes de viatge. Feconditat», comerciante relacionado como ya hemos indicado con la profesión de Vilaró, está alegre por el nuevo nacimiento de un hijo, tal y como se describe en el texto:

...és de les persones que més fonda simpatía m'inspiren d'aquell cantó d'Italia, i encara que la nostra amistat sigui purament comercial, el séu caràcter i el meu s'avenen d'una tal manera, que sovint, parlant de negoci, les nostres converses han devingut sencillament d'amics, franques, de companys, en una paraula. ${ }^{58}$

Pero tiene una gran desgracia que toda la gente conoce, aunque él intenta vivir con ella y no crear escándalo, siendo escarnecido por parte de la población. El secreto a voces es que los hijos que ha tenido no son suyos, sino de su hermano. En la conversación que tiene nuestro autor, con él y su hermano, más o menos se anticipa este hecho: «tens massa orgull quan parles dels teus fills; no semble sinó que ningú més pugui tenir-ne ${ }^{59}$ A pesar de todo esto, el cliente de Vilaró hace una defensa a ultranza de su mujer a la vez que describe a la mujer toscana:

... En té l'aire, la veu, la música de la parla; quan camina no's belluga, sembla que la terra la porti damunt dels braços... toscana... toscana, no hi ha excepció. ${ }^{60}$

Por otra parte al personaje de «Notes de viatge. Desconsol», Mario, amigo y cliente, lo va describiendo a través de una conversación con otros amigos, comunicándole que se encuentra, éste, en la cárcel. Lo hacen mediante referencias a su forma de ser, «...el séu treball honrat és el sosteniment d'un pobre vellet i d'una noia» $\mathrm{o}$ «....un xicot com ell, tant extremadament simpàtic, tant actiu, honrat i esclau del séu negoci» ${ }^{61}$. La hermana se siente culpable del destino de su hermano, que está en la cárcel por causa de un hombre que la quería ${ }^{62}$. En la visita que realiza a la cárcel ${ }^{63}$, el amigo tiene la impresión de que no ha cambiado

57 «Notes de viatge. Una nit a Messina», ETC, 145.

58 «Notes de viatge. Feconditat», ETC, 120, p. 391.

59 «Notes de viatge. Feconditat», ETC, 120, p. 393.

60 «Notes de viatge. Feconditat», ETC, 120, p. 393

${ }^{61}$ «Notes de viatge. Desconsol», ETC, 185, p. 596.

62 «Notes de viatge. Desconsol», ETC, 185, p. 597.

${ }^{63}$ La descripción de la cárcel hemos comprobado que es un espacio que no recuerda a un edificio de este tipo, sino más a un antiguo monasterio. 
mucho a pesar de su destino, pues sigue siendo la misma persona. Sólo a través de la conversación comprueba y expresa sus sentimientos; no se sentirá libre de culpa aunque sea exculpado del crimen, por que lo hizo de manera consciente ${ }^{64}$.

El personaje bohemio en «Notes de viatge. En Piccini», es alegre por su vida y por su condición. Lo describe como «aucell sense gabia» ${ }^{65}$. La conversación que tienen está basada principalmente en la vida que llevan estas personas, la cual le llama la atención a nuestro cronista como puede reflejarse en estas palabras:

Tots aquells preparatius de marxa, fets entre cants i rialles, teníen un encís per a mi inexplicable, i per això, des de sota els porxos ont jo'm trobava, les cames m'emmanaren cap an ells, instintivament. ${ }^{66}$

Se contrasta la vida de la ciudad con la vida que lleva el bohemio en la carretera, sin ataduras a un amo o a un lugar. Pero el alma algunas veces es débil, y antes del parto, se le pasó por la cabeza, por lo menos por un instante, permanecer una temporada en la ciudad hasta que naciera. Por lo que cuenta parece que el hijo nació antes de lo previsto en medio de un camino. Así describe su filosofía de la vida:

.... Aixó viu ${ }^{67}$ i no us estranyà que aixís vulgui morir el qui, com jo, va rodolant pel món i és desvetllat cada matí amb una rosada de petons que no sembla sinó que'l cavall s'ha equivocat, portant carro i persones cel amunt..., amunt, que ja ni es veu la terra...68

\section{A MANERA DE CONCLUSIÓN}

Como hemos observado a lo largo de estas páginas, Ramon Vilaró crea una serie de crónicas periodísticas que se pueden encuadrar en el género de literatura de viajes, pero en su caso no predomina el plano descriptivo aunque si otras características del género como la referencia al medio de transporte o a los compañeros de viaje, insistiendo el desarrollo del retrato de los personajes.

En estas «notes de viatge», no obstante, se realiza la descripción de dos maneras, una primera donde se describe el paisaje por donde pasa el tren, elemento característico del género, y la segunda para las ciudades. La descripción de la ciudad la acomete de dos formas: una primera, que hemos llamado descripción general de la ciudad, nos presenta la urbe a donde ha llegado, mediante dos tipos de descripción ya mencionados, a través de la impronta sentimental y de la notificación física del conjunto; y un segundo tipo, el especifico, donde se descri-

\footnotetext{
${ }^{64}$ «Notes de viatge. Desconsol», ETC, 185, p. 599.

65 «Notes de viatge. En Piccini», ETC, 105, p. 150.

66 «Notes de viatge. En Piccini», ETC, 105, p. 150.

${ }^{67}$ Se refiere que vive en la carretera.

68 «Notes de viatge. En Piccini», ETC, 105, p. 151.
} 
be un elemento representativo, edificio o espacio focalizado dentro de la geografía urbana, es decir una casa, una iglesia, una plaza...., utilizándolo como elemento introductorio para el diálogo y el desarrollo psicológico de los personajes que allí se encuentra.

Como hemos analizado y comprobado el desarrollo psicológico de los personajes lo consigue mediante el empleo de la técnica del diálogo y las impresiones que recibe el autor. Los personajes aquí presentados, tanto jóvenes como mayores, tienen una característica común, la desgracia. Estos personajes están marcados, en gran medida, por los daños sufridos en la I Guerra Mundial, las mutilaciones en el caso de los soldados, la pérdida de algún familiar, etc.; pero también existen otras causas de las desgracias, como la enfermedad.

A su vez, como ya hemos visto, se enfrentan diferentes personajes de las crónicas mediante diferentes motivos, creando parejas de opuestos: por su juventud, por su estado social, por la manera de afrontar su desgracia, etc. Todas estas formas de comportamiento son desarrolladas a través del diálogo y las descripciones de los personajes.

\section{BIBLIOGRAFÍA}

- Textos

— «Notes de viatge. O’Marenà», El Teatre Català, 95 (20-XII-1913), pp. 878-879.

— «Notes de viatge. La noia rossa», El Teatre Català, 100 (24-II-1914), pp. 54-56.

— «Notes de viatge. En Piccini», El Teatre Català, 105 (28-II-1914), pp. 149-151.

— «Notes de viatge. L'invàlid», El Teatre Català, 107 (14-III-1914), pp. 182-185.

— «Notes de viatge. El guarda agulles», El Teatre Català, 111 (11-IV-1914), pp. 261262.

— «Notes de viatge. El guarda agulles», El Teatre Català, 114 (2-V-1914), pp. 294295.

— «Notes de viatge. Passionaria», El Teatre Català, 117 (23-V-1914), pp. 340-342.

— «Notes de viatge. Feconditat», El Teatre Català, 120 (13-VI-1914), pp. 391-394.

— «Notes de viatge. La cega», El Teatre Català, 126 (25-VII-1914), pp. 486-489.

— «Notes de viatge. La noia gran», El Teatre Català, 136 (3-X-1914), pp. 649-653.

— «Notes de viatge. Passant la França», El Teatre Català, 141 (7-XI-1914), pp. 728730 .

— «Notes de viatge. Una nit a Messina», El Teatre Català, 145 (5-XII-1914), pp. 787-789.

— «Notes de viatge. Desconsol», El Teatre Català, 185 (11-IX-1915), pp. 595-600.

— «Notes al vol, d'un viatge en temps de guerra», El Teatre Català, 198 (11-XII-1915), pp. 804-805. 
- «Notes al vol, d'un viatge en temps de guerra. El pobre mut», El Teatre Català, 199 (18-XII-1915), pp. 825-827.

- Referencias Bibliográfícas

- Arbillaga, Idoia: Estética y teoría del libro de viaje. El 'viaje a Italia' en España, Málaga, Analecta Malacitana, 2005.

- Lladó I Vilaseca, Jordi: Ramon Vinyes i el teatre (1904-1939), tesis doctoral dirigida por Jordi Castellanos i Vila, Universitat de Barcelona, 2002.

- Machado, A. M. y A. H. Pageaux, «As experiências da viagem» en Da literatura comparada à teoria da literatura, Lisboa, Fundamentos, 2001, pp. 33-47.

- PÉrez Priego, M. A.: «Estudios literarios de los libros de viajes medievales», Epos, 1 (1984), pp. 217-239.

- Riquer, Martín de (dir.): Història de la Literatura Catalana, vol. VIII, Barcelona, Ariel, 1986.

- VV. AA.: Diccionari de la literatura catalana, Barcelona, Edicions 62, 1979. 